ARTICLE

DOI: $10.1038 / \mathrm{s} 41467-017-01483-7$

\title{
The structural basis of proton driven zinc transport by ZntB
}

Cornelius Gati ${ }^{1}$, Artem Stetsenko (10 ${ }^{2}$, Dirk J. Slotboom², Sjors H.W. Scheres ${ }^{1}{ }^{1} \&$ Albert Guskov (1) ${ }^{2}$

Zinc is an essential microelement to sustain all forms of life. However, excess of zinc is toxic, therefore dedicated import, export and storage proteins for tight regulation of the zinc concentration have evolved. In Enterobacteriaceae, several membrane transporters are involved in zinc homeostasis and linked to virulence. ZntB has been proposed to play a role in the export of zinc, but the transport mechanism of ZntB is poorly understood and based only on experimental characterization of its distant homologue CorA magnesium channel. Here, we report the cryo-electron microscopy structure of full-length ZntB from Escherichia coli together with the results of isothermal titration calorimetry, and radio-ligand uptake and fluorescent transport assays on ZntB reconstituted into liposomes. Our results show that $\mathrm{ZntB}$ mediates $\mathrm{Zn}^{2+}$ uptake, stimulated by a $\mathrm{pH}$ gradient across the membrane, using a transport mechanism that does not resemble the one proposed for homologous CorA channels.

\footnotetext{
${ }^{1}$ MRC Laboratory of Molecular Biology, Francis Crick Avenue, Cambridge Biomedical Campus, Cambridge CB2 OQH, UK. ${ }^{2}$ Groningen Biomolecular Sciences and Biotechnology Institute, University of Groningen, Nijenborgh 4, 9747AG Groningen, The Netherlands. Cornelius Gati and Artem Stetsenko contributed equally to this work. Correspondence and requests for materials should be addressed to S.H.W.S. (email: scheres@mrc-Imb.cam.ac.uk) or to A.G. (email: a.guskov@rug.nl)
} 
Z inc is one of the few 'essential-but-also-toxic' divalent cations required for the cell and is an important 'token coin' in host:pathogen interactions ${ }^{1}$ : whenever host organisms try to sequester all available zinc at the host:pathogen interface to reduce the virulence of invading bacteria ${ }^{2}$, the latter employ highly specific uptake systems to scavenge zinc $^{3}$. Conversely, if the zinc concentration is elevated in hosts to oppress pathogens ${ }^{4}$, the latter regulate their intracellular zinc concentration by scaling up the export of zinc ${ }^{3}$. Due to this ambidexterity, the tight regulation of zinc homeostasis is crucial. Different bacteria cope with this task in a variety of ways-for example, by storage of zinc by metallothioneins as in cyanobacteria $^{5}$, by assembly of redundant importers as in Cupriavidus metallidurans ${ }^{6}$ or via a controlled shunt of zinc export-import as in Escherichia coli, where zinc-iron permeases (ZIPs) family transporter $\mathrm{ZupT}^{7}$ and the ATP-binding cassette (ABC) transporter $\mathrm{ZnuABC} \mathrm{C}^{8,9}$ are recruited for import, and P-type ATPase $\mathrm{ZntA}^{10}$ and cation-diffusion facilitator YiiP ${ }^{11}$ for export of zinc (Supplementary Fig. 1). In addition, the zinc transporter ZntB, which belongs to the CorA metal ion transporter (MIT) family is widespread in Enterobacteriaceae ${ }^{12,13}$. There is controversy over the question whether $\mathrm{ZntB}$ is an exporter ${ }^{12}$ or importer ${ }^{6}$. Furthermore, mechanistic insight is lacking because crystal structures are available of only cytoplasmic parts of $\mathrm{ZntB}^{14,15}$, and scarce transport activity measurements have been performed only in whole cells. We have obtained the structure of full-length ZntB from E. coli and performed isothermal titration calorimetry (ITC), radiolabelled zinc uptake and fluorescent transport experiments with $\mathrm{ZntB}$ reconstituted into liposomes. This study shows that $\mathrm{ZntB}$ mediates $\mathrm{Zn}^{2+}$ transport, which is stimulated by a $\mathrm{pH}$ gradient across the membrane. The comparison of the full-length structure of $\mathrm{ZntB}$ with previously resolved structures of $\mathrm{ZntB}$ soluble domains in different conditions (in the presence and absence of $\mathrm{Zn}^{2+}$ ) and structures of homologous CorA proteins, is indicative that $\mathrm{ZntB}$ and CorA proteins utilize different transport mechanisms.

\section{Results}

Structure of ZntB. The apo structure of $\mathrm{ZntB}$ was obtained by single-particle cryo-electron microscopy (cryo-EM) using $n$-dodecyl- $\beta$-D-maltopyranoside (DDM)-solubilized and purified E. coli ZntB (EcZntB) (pre-treated with ethylenediaminetetraacetic acid (EDTA)) and resolved at an overall resolution of $4.2 \AA$ (Supplementary Figs. 2 and 3, Table 1). The structure of $\mathrm{ZntB}$ revealed a pentameric arrangement (Fig. 1a, b), similar to that reported for other members of the CorA family ${ }^{13,16,17}$ (Supplementary Fig. 4) even though CorA and ZntB share very little sequence identity (below 20\%) (Supplementary Fig. 5). Each protomer of $\mathrm{ZntB}$ consists of a large $\mathrm{N}$-terminal cytoplasmic domain folded into an $\alpha \beta \alpha$ motif. A long $\alpha$-helix protrudes from the cytoplasmic domain into the membrane (TM1) and is joined to a second transmembrane helix (TM2) (Fig. 1a) via the only periplasmic loop, which bears the signature motif $\mathrm{GxN}$ of the CorA MIT family ${ }^{13}$ (Fig. 1b, c). In the resolved structure of EcZntB, the cytoplasmic domain is very similar to the isolated domain of ZntB from Vibrio parahaemolyticus $(\mathrm{Vp})^{14}$ (rmsd $\sim 2.5 \AA$ ), but significantly different from the homologous domain of Salmonella typhimirium (St) $\mathrm{ZntB}^{15}$ (rmsd $12 \AA$ ). Taking into account very high sequence conservation between EcZntB and StZntB of $92.6 \%$ (Supplementary Fig. 5), the structural difference is intriguing. This difference could be attributed to the two structures representing two different states in the transport cycle (discussed below). Analysis of the substrate translocation pore revealed a wider profile in $\mathrm{ZntB}$ than in the magnesium channels TmCorA and MjCorA (Supplementary Fig. 6). All three proteins have short extracellular loops between TM1 and TM2, where the family signature motif GxN that forms the selectivity filter (Fig. 1b, c) is located. Whereas in CorA proteins the signature motif has the sequence GMN, ZntBs show a Met to Val substitution, potentially having consequences for the substrate recognition, as in $\mathrm{ZntB}$, the radius of the filter is $\sim 4.5$ vs 3.5-4.0 ̊ in CorAs (Fig. 1d).

Substrate selectivity of ZntB. One of the puzzling features of the CorA family is substrate selectivity. The geometry of the selectivity filter is thought to define the correct distances between (partially) hydrated cation and amino acid side chains of the filter, and hence recognition ${ }^{18,19}$. Intriguingly, although the hydrated radii of known transported substrates for the CorA family are very similar $\left(2.10 \AA, 2.09 \AA, 2.10 \AA, 2.07 \AA\right.$ for $\mathrm{Zn}^{2+20}$, $\mathrm{Mg}^{2+21}, \mathrm{Co}^{2+21,22}$ and $\mathrm{Ni}^{2+23}$, respectively) and all these cations have a similar octahedral arrangement of six water molecules in their first hydration shell in aqueous solution; different subfamilies have distinct substrate specificities. It has been proposed that this selectivity might be based on the rigidity of ion solvation shells and rates of water exchange ${ }^{18}$.

To characterize the specificity, we performed ITC experiments and fluorescent transport assays. ITC experiments revealed binding of $\mathrm{Zn}^{2+}, \mathrm{Cd}^{2+}, \mathrm{Ni}^{2+}$ and $\mathrm{Co}^{2+}$ to $\mathrm{ZntB}$, with $K_{\mathrm{d}}$ values of $11.5,22.6,87.7$ and $175.4 \mu \mathrm{M}$, respectively, in 1:1 stoichiometry
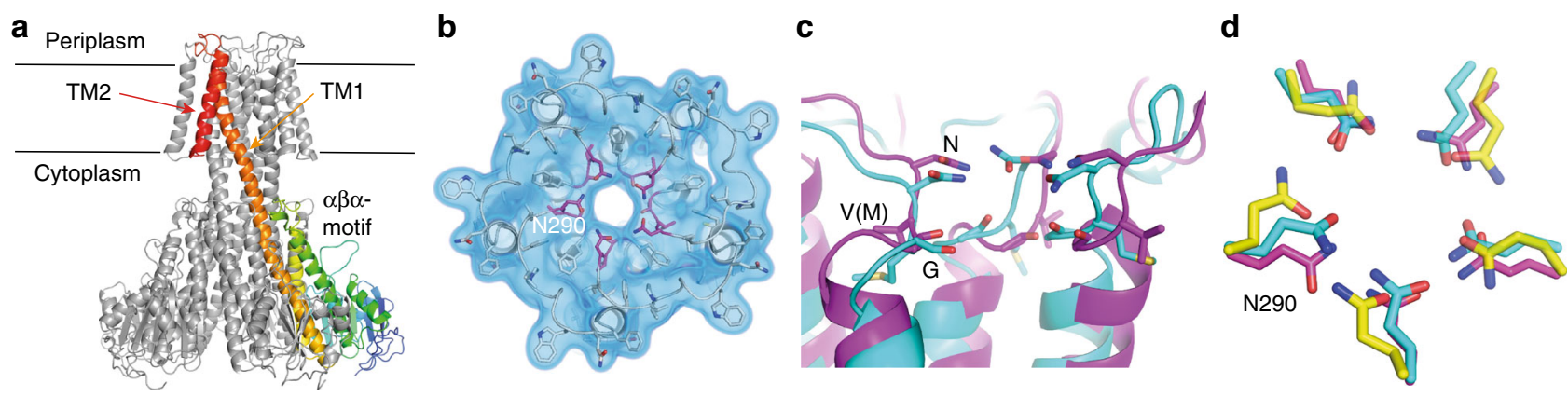

Fig. 1 The structure of the full-length ZntB. a Side view, four subunits of ZntB pentamer are coloured grey, and one is coloured rainbow from blue (N-terminus) to red (C-terminus); the position of the membrane is indicated, trans membrane helices 1 and 2 as well as $\alpha \beta \alpha$-motif are labelled. $\mathbf{b}$ Top view (from periplasm) onto $\mathrm{ZntB}-10$ trans membrane helices are arranged cylindrically, with TM2 ring at the periphery. Experimental density is contoured in blue. The connecting loops provide residues for the selectivity filter (in magenta), further exemplified in (c) structural comparison of selectivity filters from EcZntB (magenta) and TmCorA (cyan), only three out five monomers are shown (d). The overlay of Asn rings (of GxN motif) from ZntB (magenta), TmCorA (cyan) and MjCorA (yellow). Note that ZntB forms a slightly wider entry point to the pore 
(Fig. 2). No binding of $\mathrm{Mn}^{2+}, \mathrm{Mg}^{2+}$ and $\mathrm{Cu}^{2+}$ was detected. The ability of $\mathrm{ZntB}$ proteins to select $\mathrm{Zn}^{2+}$ over $\mathrm{Mg}^{2+}$, and conversely the ability of CorA proteins to select $\mathrm{Mg}^{2+}$ over $\mathrm{Zn}^{2+}$, may be explained by different sizes of the pore-the substitution of a

a

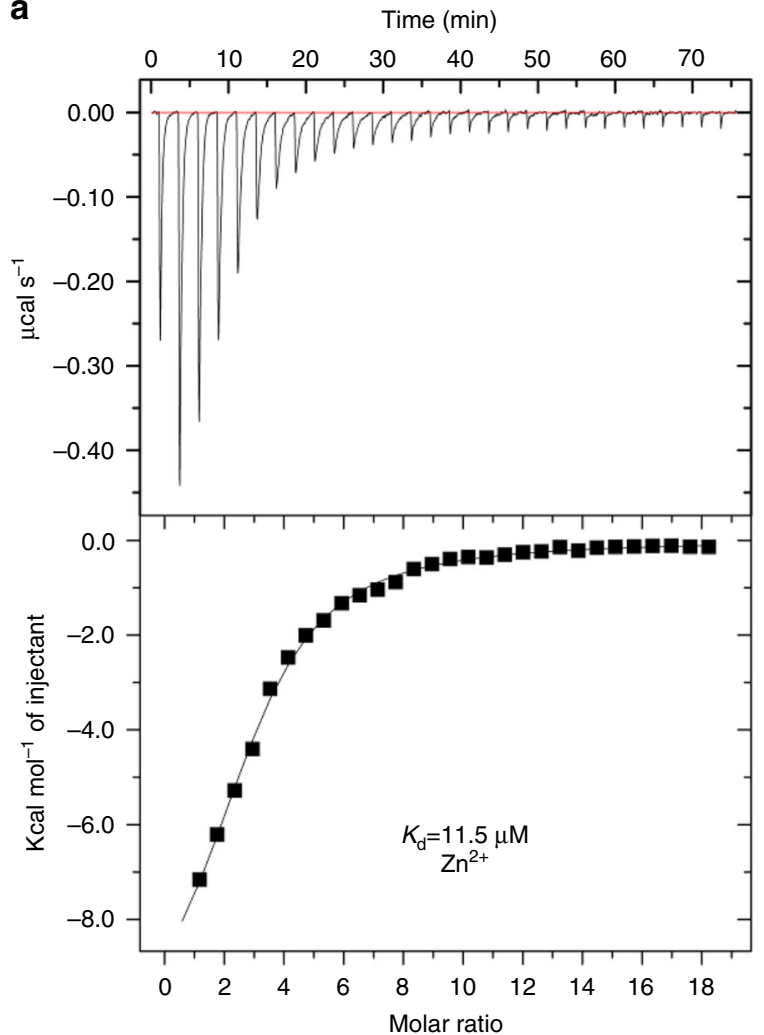

C

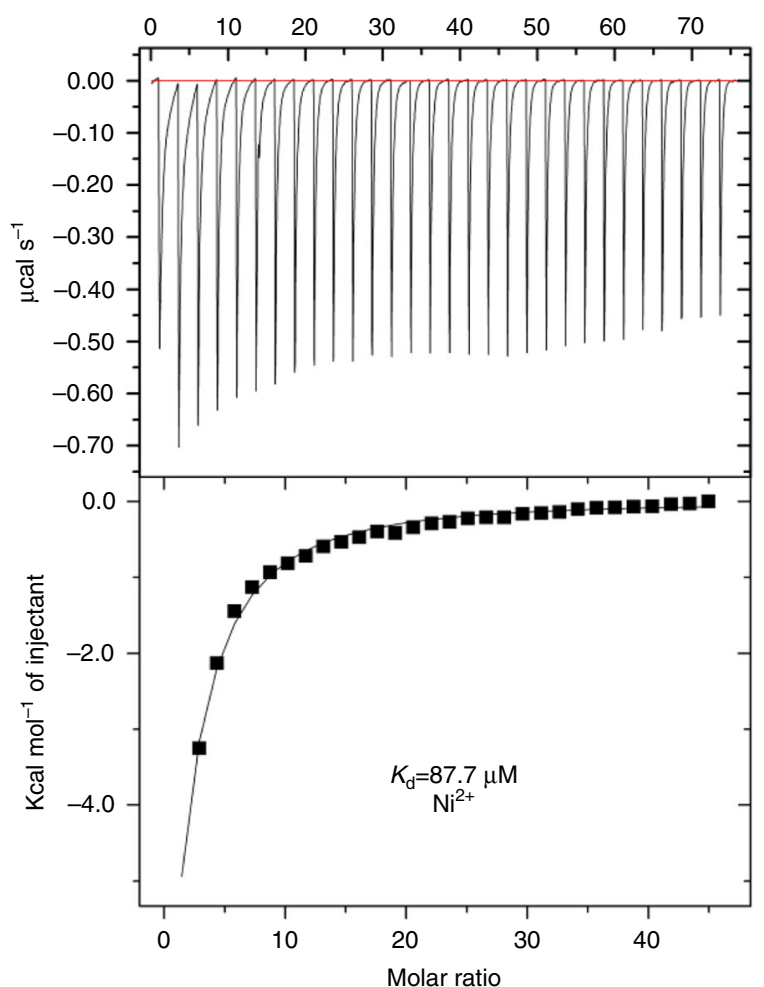

single amino acid in the signature motif (see above) might be enough. However, $\mathrm{Co}^{2+}$ and $\mathrm{Ni}^{2+}$ appear to be substrates of both $\mathrm{ZntB}$ and CorA $\mathrm{A}^{24,25}$, thus the precise determinants of selectivity are still elusive. We additionally tested the transport of the cations

b

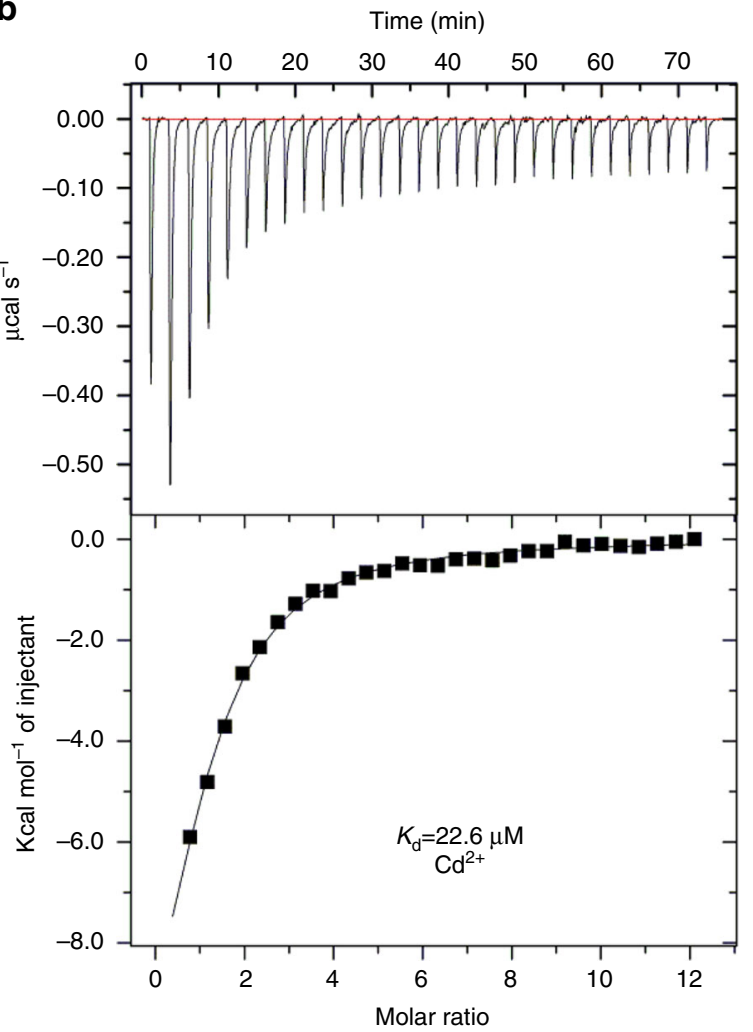

d

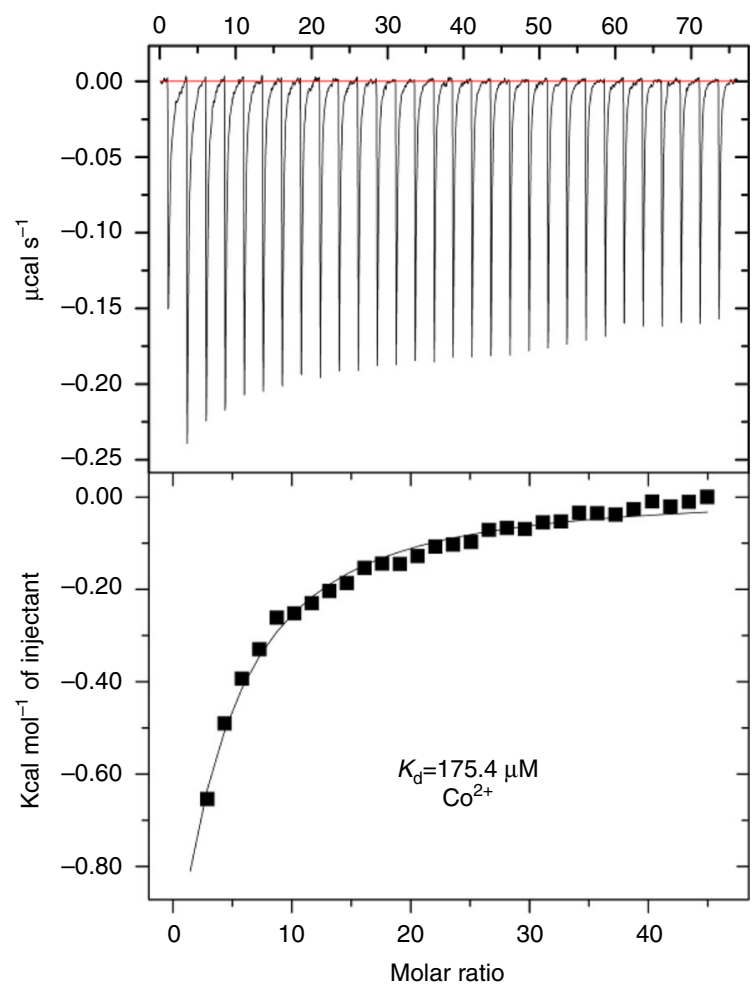

Fig. 2 ITC profiles of substrate binding to $\mathrm{ZntB}$ of (a) $\mathrm{Zn}^{2+}$ (b) $\mathrm{Cd}^{2+}$ (c) $\mathrm{Ni}^{2+}$ (d) $\mathrm{Co}^{2+}$ 
a

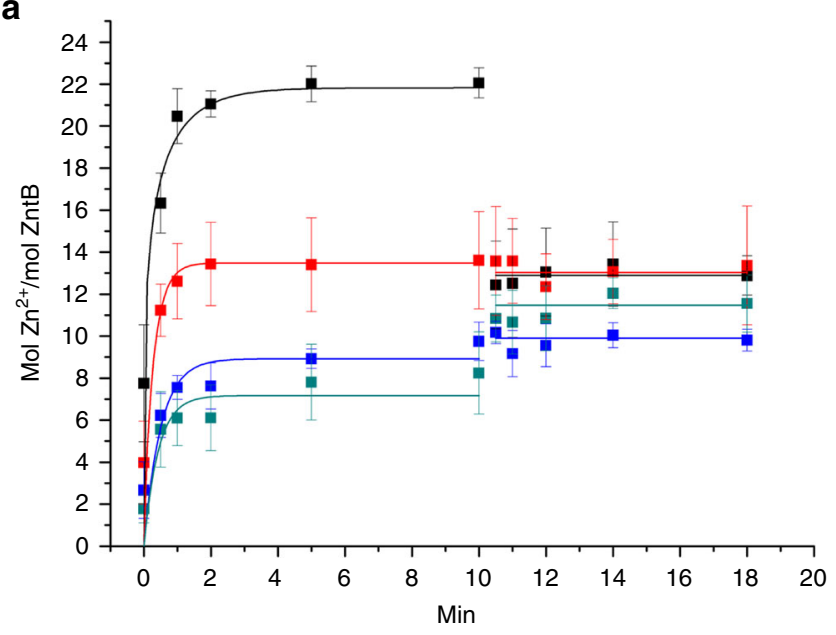

C

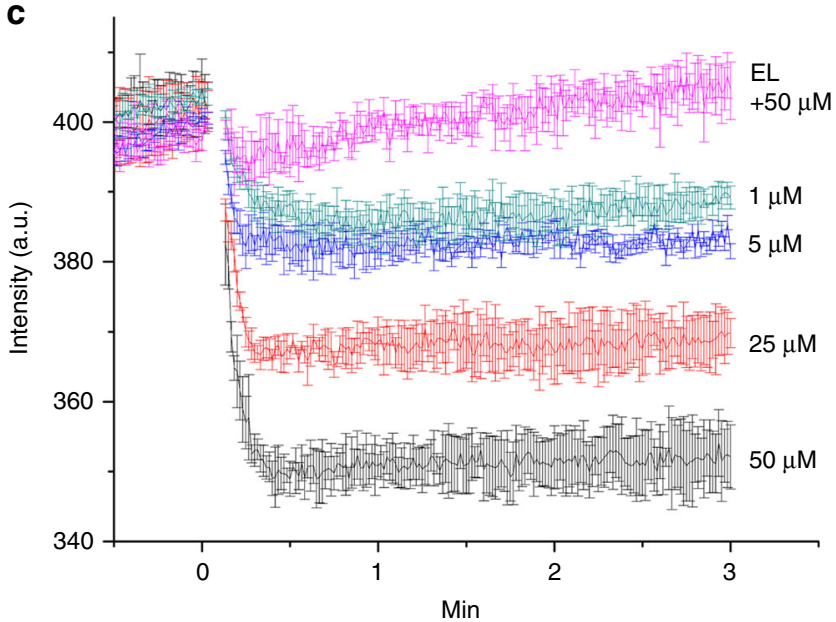

b

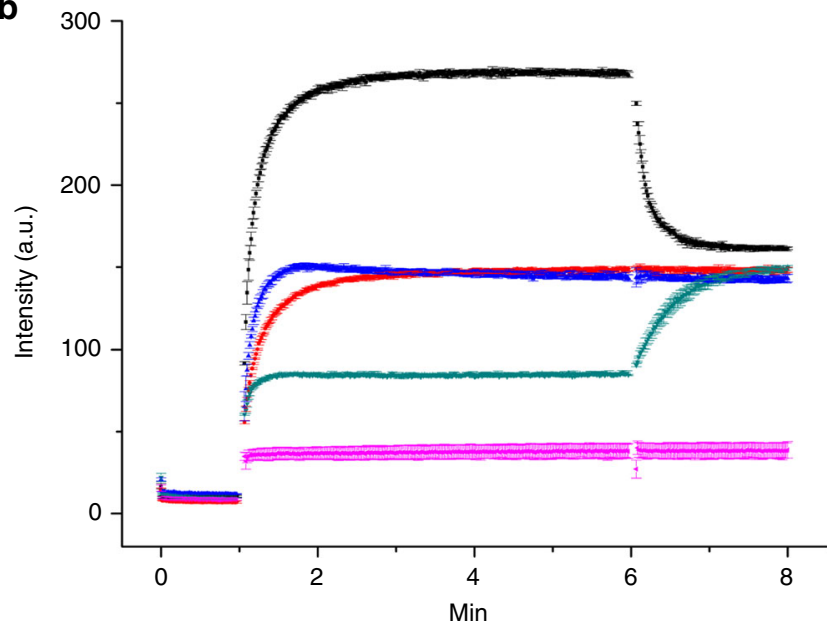

d

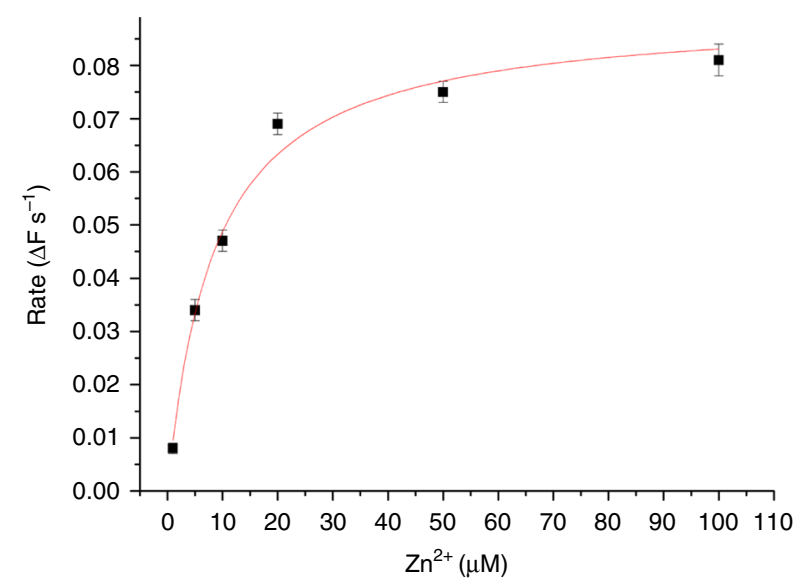

Fig. 3 Radioactive and fluorescent transport assays (a) ${ }^{65} \mathrm{Zn}^{2+}$ uptake via $\mathrm{ZntB}$ reconstituted in liposomes under different conditions (colour-coded: blackinward pH flux (7.5 in/6.5 out); green-outward pH flux (6.5 in/7.5 out); red and blue-no pH flux at 6.5 and 7.5 pH, respectively). lonophore FCCP was added at the time point of $10 \mathrm{~min}$. Note the opposite effect of FCCP on direct and reverse $\mathrm{pH}$ gradient. Error bars represent s.e.m. from more than three technical replicates of independent batches of proteoliposomes. $\mathbf{b}$ Changes in fluorescent signal by the reporter dye FluoZin- 1 during uptake of $\mathrm{Zn}^{2+}$ (added at $1 \mathrm{~min}$ time point) via ZntB reconstituted in liposomes under different conditions (colour-coding as in a, additionally the signal from empty liposomes in magenta). FCCP was added at the time point of $6 \mathrm{~min}$. Error bars represent s.e.m. from more than three technical replicates of independent batches of proteoliposomes. c $\mathrm{Zn}^{2+}$-dependent transport of $\mathrm{H}^{+}$via $\mathrm{ZntB}$. Quenching of the $\mathrm{pH}$-dependent fluorophore $\mathrm{ACMA}$ at different $\mathrm{Zn}^{2+}$ concentrations is shown by unique colours. $\mathbf{d}$ Rate of transport dependence on $\mathrm{Zn}^{2+}$ concentration. The solid line represents the fit to the Michaelis-Menten equation with a $K_{\mathrm{M}}$ of $\sim 7.5 \mu \mathrm{M}$ (based on FluoZin-1 experiments)

by $\mathrm{ZntB}$ reconstituted into the liposomes, and found that the ions that bind to the protein in ITC assay are also transported (see below).

Zinc transport by $\mathrm{ZntB}$ is stimulated by $\mathbf{p H}$ gradient. To characterize the mode of transport, we performed the ${ }^{65} \mathrm{Zn}^{2+}$ uptake assays with purified $\mathrm{ZntB}$ reconstituted into liposomes. Transport was measured using either equal $\mathrm{pH}$ on the inside and outside of the liposomes, or using $\mathrm{pH}$ gradients. $\mathrm{Zn}^{2+}$ was taken up by the liposomes containing ZntB, and uptake was enhanced by a $\mathrm{pH}$ gradient with the lumen of the liposomes more basic than the outside. In contrast, uptake was suppressed in the presence of a reverse $\mathrm{pH}$ gradient. These experiments suggest that zinc transport is driven by the $\mathrm{pH}$ gradient. Consistently, addition of the proton ionophore FCCP at a time point when the uptake had reached a plateau led to efflux of the accumulated ${ }^{65} \mathrm{Zn}^{2+}$ in case of a $\mathrm{pH}$ gradient that was basic inside (Fig. 3a), and addition of FCCP to liposomes with the opposite $\mathrm{pH}$ gradient stimulated additional uptake. FCCP did not affect the $\mathrm{Zn}^{2+}$ accumulation in the absence of a $\mathrm{pH}$ gradient (Fig. 3a). These results were confirmed by performing the transport assays with the specific zinc reporting dye fluozin- ${ }^{26}$, encapsulated into liposomes. The fluorescence signal increased upon $\mathrm{Zn}^{2+}$ transport into the liposomes and FCCP had a similar effect as in uptake assays with radiolabelled $\mathrm{Zn}^{2+}$ (Fig. $3 \mathrm{~b}$ ). The observed stimulation of $\mathrm{Zn}^{2+}$ uptake by an inward $\mathrm{pH}$ gradient suggests a mechanism in which protons are co-transported with $\mathrm{Zn}^{2+}$. We directly measured $\mathrm{Zn}^{2+}$-dependent proton transport using $\mathrm{pH}$-sensitive fluorophore 9-amino-6-chloro-2-methoxyacridine (ACMA) (Fig. 3c) with proteoliposomes that had equal $\mathrm{pH}$ in the lumen and exterior. $\mathrm{Zn}^{2+}$ uptake into these proteoliposomes was accompanied by generation of a $\mathrm{pH}$ gradient, consistent with coupled $\mathrm{H}^{+}-\mathrm{Zn}^{2+}$ transport mechanism. A Na${ }^{+}$gradient instead of a proton gradient did not stimulate transport (Supplementary Fig. 7). These experiments show that $\mathrm{Zn}^{2+}$ transport is stimulated 


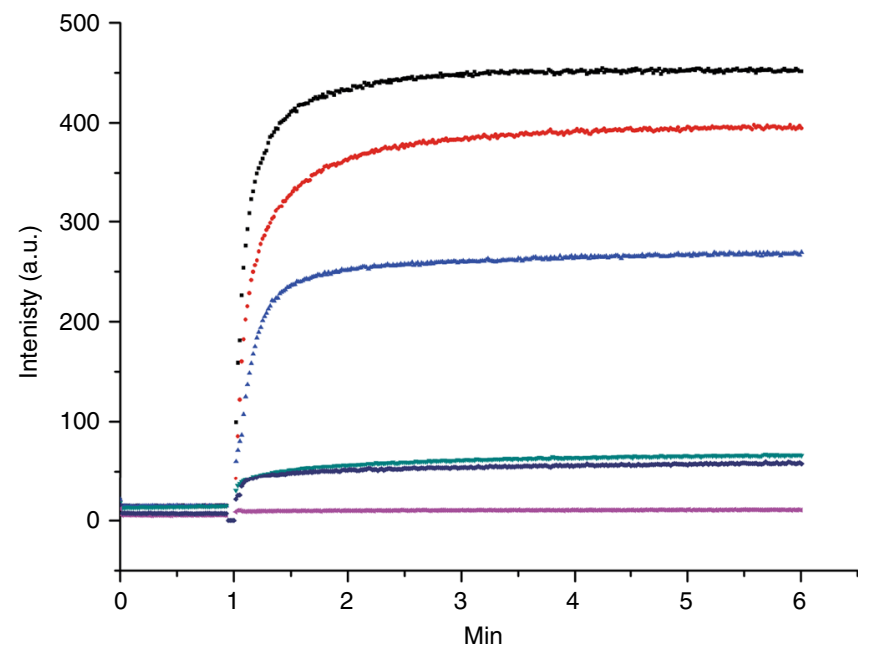

Fig. 4 Transport of different cations by ZntB. Transport of different cations (added at $1 \mathrm{~min}$ and colour-coded: black-20 $\mu \mathrm{M} \mathrm{Zn}^{2+}$, red-20 $\mu \mathrm{M} \mathrm{Cd}^{2+}$, blue-100 $\mu \mathrm{M} \mathrm{Ni}^{2+}$, green-200 $\mu \mathrm{M} \mathrm{Co}^{2+}$, dark blue-empty liposomes with $20 \mu \mathrm{M} \mathrm{Zn}^{2+}$, magenta-empty liposomes with $200 \mu \mathrm{M} \mathrm{Co}^{2+}$ ) assayed by the fluorophore Fluozine- 1 trapped inside the proteoliposomes

by a proton gradient across the membrane. Finally, the transport of $\mathrm{Zn}^{2+}$ saturated with increasing $\mathrm{Zn}^{2+}$ concentrations with a $K_{\mathrm{M}}$ of $\sim 7.5 \mu \mathrm{M}$ (Fig. 3d), again indicative of a transporter mechanism.

To complement the ITC experiments on substrate binding (see above), we tested whether $\mathrm{Ni}^{2+}, \mathrm{Co}^{2+}, \mathrm{Cd}^{2+}$ could be transported by $\mathrm{ZntB}$ reconstituted into the liposomes using the fluozin-1 dye, and observed comparable levels of transport for $\mathrm{Ni}^{2}$ ${ }^{+}$and $\mathrm{Cd}^{2+}$, but not for $\mathrm{Co}^{2+}$. The failure to detect transport of $\mathrm{Co}^{2+}$ is likely caused by lower sensitivity of the dye for this cation (Fig. 4).

\section{Discussion}

$\mathrm{ZntB}$ is a distant homologue of CorA proteins, which are wellcharacterized magnesium (and cobalt) channels ${ }^{13,16,17,27}$. Based on whole-cell transport experiments on $\mathrm{ZntB}^{12}$ and structures of soluble domains ${ }^{14,15}$, it has been proposed that CorA superfamily contains both channels (CorA) and transporters ( $\mathrm{ZntB})$, the latter possibly using a different transport mechanism ${ }^{12}$. A recently reported cryo-EM structure of TmCorA in $\mathrm{Mg}^{2+}$-free conditions, obtained upon EDTA treatment, revealed an unprecedented asymmetry of the pentamer ${ }^{28}$. It was concluded that CorA proteins might use a transport mechanism that involves a partial loss of the fivefold symmetry in the open state ${ }^{28-30}$ to create a pore wide enough for the transport of partially hydrated magnesium. Our work on ZntB shows that the mechanism cannot be extrapolated to other members of the family, because even after an extensive treatment with EDTA ZntB maintained its symmetrical pentameric state (Supplementary Fig. 8). There are several possible explanations for the differences between CorA and ZntB. First, the structural differences are genuine, and related to mechanistic differences between CorA and ZntB. Second, ZntB can also form a collapsed state, but under different conditions than CorA (perhaps in the membrane). Third, the observed symmetry-collapsed state of CorA is an artefact, possibly induced by the $\mathrm{Mg}^{2+}$-free conditions that were used to obtain the structure. Such conditions are probably never encountered by the protein under physiological conditions, as the intracellular concentration of free $\mathrm{Mg}^{2+}$ is estimated to be around $0.5-1 \mathrm{mM}^{31}$. Also, other intracellular divalent and monovalent cations were shown to bind to TmCorA ${ }^{30}$. Therefore, it is possible that the observed symmetry-collapsed structure is not part of the mechanism of channel opening. In contrast to stringent removal of $\mathrm{Mg}^{2+}$ from CorA channels, the depletion of $\mathrm{Zn}^{2+}$ from $\mathrm{ZntB}$ is likely to be physiologically relevant because intracellular concentrations of free $\mathrm{Zn}^{2+}$ are extremely low (i.e., in the $\mathrm{pM}-\mathrm{fM}$ range $^{32,33}$ ). Therefore the symmetrical structure of $\mathrm{ZntB}$ may better represent the apo state than the asymmetrical structure of CorA.

To understand the mechanism of transport used by $\mathrm{ZntB}$, the structures of the different states are essential. A comparison of our full-length structure with the structure of the soluble domain of StZntB provides a first indication of the movements that may occur within the symmetrical scaffold to provide a pathway for the transported zinc (Fig. 5). Whereas our structure was obtained in the absence of $\mathrm{Zn}^{2+}$, StZntB was crystallized in the presence of $\mathrm{Zn}^{2+}$. Calculation of the surface potentials revealed dramatic differences between full-length EcZntB and soluble StZntB (Fig. 5a, b). The cytoplasmic domain of full length EcZntB has a strong positive electrostatic surface potential (resembling VpZntB (Fig. 5c)), whereas the potential in the isolated domain of StZntB is negative ${ }^{15}$. Threading of the EcZntB sequence in the StZntB produced a similar result of more negative surface potential (Fig. 5d) and the reverse threading (StZntB sequence in EcZntB model) produced a positive surface potential (Fig. 5e). Furthermore, the shape of the internal pore between two forms is different (Fig. 5) possibly resembling two conformational states. The charge inversion of the pore surface (Fig. 5f) between the two symmetrical states might be caused by helical rotation of TM1, which bears a patch of highly conserved basic and acidic residues on the adjacent faces of the helix.

It has been debated whether ZntB is primarily used for import or export. Whole-cell assays have indicated that $\mathrm{ZntB}$ is a $\mathrm{Zn}^{2+}$ and $\mathrm{Cd}^{2+}$ exporter $^{12}$. This conclusion was based on experiments using a knockout strain, from which it was assumed that all zinc transporters had been deleted. However, recent studies revealed that additional transporters, such as $\operatorname{Pit}^{6}, \operatorname{HoxN}, \operatorname{ActP}^{34}$ and the STM0353 gene product (homologous to $\mathrm{CadA}^{35}$ ), might contribute significantly to zinc transport. Nevertheless, these results showed that $\mathrm{ZntB}$ at least affected the transport of $\mathrm{Zn}^{2+}$ and $\mathrm{Cd}^{2}$ ${ }^{+}$. Interestingly, the analysis of regulation of $\mathrm{ZntB}$ expression in $C$. metallidurans revealed that it was downregulated in the presence of high concentrations of $\mathrm{Zn}^{2+}, \mathrm{Cd}^{2+}$ and $\mathrm{Cu}^{2+6}$, which suggests that it is an importer, rather than an exporter. Additionally the expression of homologous $\mathrm{ZntB}$ from Agrobacterium tumefaciens was not induced by treatments with $\mathrm{Zn}^{2+}$ in a range from 100 to $750 \mu \mathrm{M}^{36}$. Our experiments show that $\mathrm{ZntB}$ most likely mediates $\mathrm{Zn}^{2+} / \mathrm{H}^{+}$co-transport, and thus indicate that $\mathrm{ZntB}$ is an importer for zinc. This indeed confirms that the same fold within CorA superfamily can be used either as a channel (CorA) or a transporter (ZntB).

In conclusion, we have resolved the full-length structure of a ZntB transporter, a member of the CorA MIT family. We have performed ligand binding and ligand-transport assays that unambiguously show that $\mathrm{ZntB}$ is involved in zinc transport. By combining all available data from us and other groups, we conclude that $\mathrm{ZntB}$ is a zinc importer that is driven by a proton gradient. Its transport mechanism appears distinct from that of CorA $\mathrm{Mg}^{2+}$ channels. Unlike CorA, ZntB does not collapse into a highly asymmetrical state upon depletion of divalent cations. The elucidation of different conformational states of $\mathrm{ZntB}$ will be essential to describe its transport mechanism in greater detail.

\section{Methods}

Protein expression and membrane vesicle preparation. Expression of $\mathrm{ZntB}$ was performed in a 5-1 flask containing $2 \mathrm{l}$ of LB medium $\left(10 \mathrm{gl}^{-1}\right.$ Bacto trypton, $5 \mathrm{gl}^{-1}$ Bacto yeast extract, $10 \mathrm{~g} \mathrm{l}^{-1} \mathrm{NaCl}$ ), supplemented with $50 \mu \mathrm{g} \mathrm{ml}^{-1}$ kanamycin and $34 \mu \mathrm{g} \mathrm{ml}^{-1}$ chloramphenicol. The E. coli BL-21(DE3) cells with pNIC_BSA4_ZntB 
a

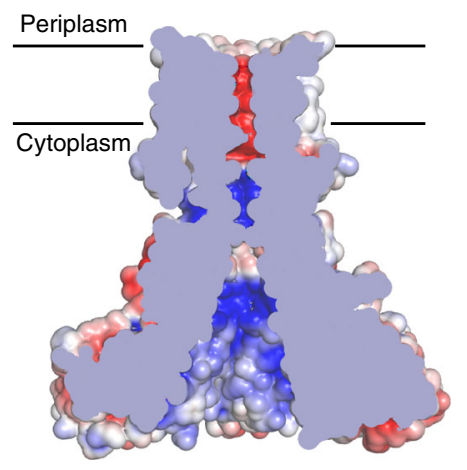

b

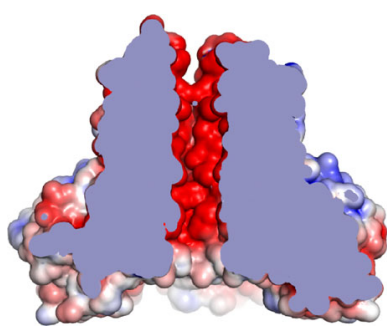

C

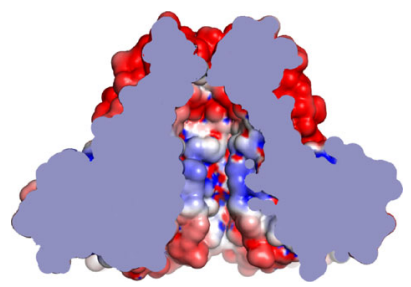

d

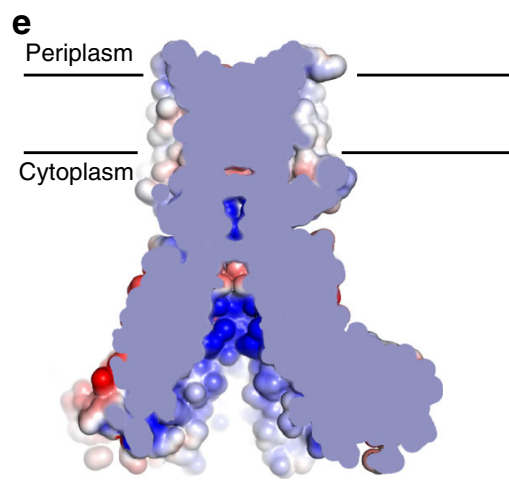
f OO

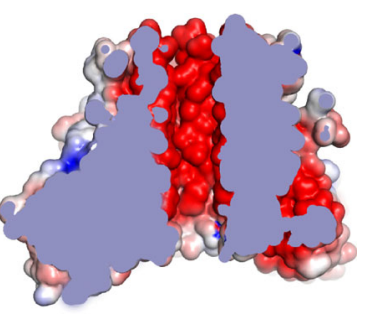

e

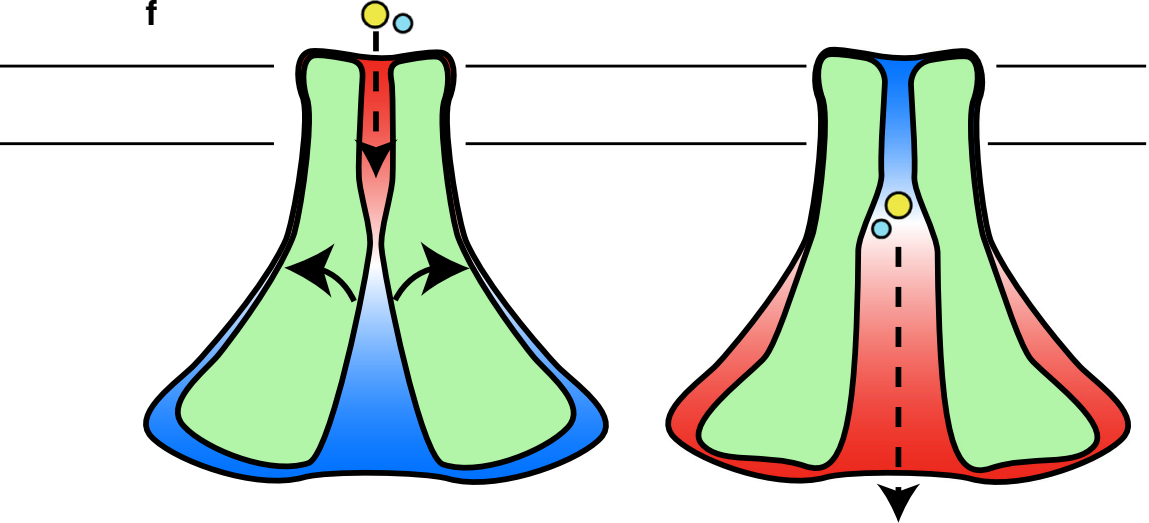

Fig. 5 Possible mechanism of $Z n^{2+}$ transport by $Z n t B$. a Calculated electrostatic potential $\left( \pm 5 k T e^{-1}\right)$ of $Z n t B$ (cross-section of the pore is shown) (b) same for $Z^{2+}$-bound soluble domain of StZntB and (c) $Z n^{2+}$-free soluble domain of VpZntB. d Phyre2-based model of putative $Z n^{2+}-$ bound EcZntB using StZntB as a template (pdb id 3NWI). e Phyre2-based model of full-length apo StZntB using EcZntB as a template. $\mathbf{f}$ Putative mechanism of $Z n^{2+}$ transport via $Z n t B$. $\mathrm{ZntB}$ cross-section is shown schematically; $\mathrm{Zn}^{2+}$ and $\mathrm{H}^{+}$are shown as yellow and cyan spheres, respectively; arrows indicate possible movements of trans membrane helix 1, which are possibly caused by $\mathrm{Zn}^{2+}$ and/or $\mathrm{H}^{+}$binding, eventually leading to the change in electrostatic potential (from positive (blue) to negative (red)) within the pore that stimulates ion advancement through it

(pNIC28-Bsa4 was a gift from Opher Gileadi (Addgene plasmid \#26103) ${ }^{37}$ ) were grown at $37^{\circ} \mathrm{C}, 200$ r.p.m. to an $\mathrm{OD}_{600}$ of 0.8 , with an induction by addition of $0.1 \mathrm{mM}$ IPTG. After $3 \mathrm{~h}$ of expression, the cells were collected by centrifugation $\left(15 \mathrm{~min}, 7446 \times g, 4^{\circ} \mathrm{C}\right)$, washed in buffer $\mathrm{A}(50 \mathrm{mM}$ Tris/ $\mathrm{HCl}, \mathrm{pH} 8.0)$ and resuspended in the buffer B $(50 \mathrm{mM}$ Tris/ $\mathrm{HCl}, \mathrm{pH} 8.0,150 \mathrm{mM} \mathrm{NaCl}, 10 \mathrm{mM}$ imidazole, $10 \%$ glycerol). Straight away, membrane vesicles were prepared or alternatively the resuspended cells were flash-frozen in liquid nitrogen and stored at $-80^{\circ} \mathrm{C}$.

$\mathrm{MgSO}_{4}$ of $1 \mathrm{mM}$ and $50-100 \mu \mathrm{g} \mathrm{ml}^{-1}$ DNase were added to the cells before membrane vesicle preparation. Next, the cells were disrupted and lysed by highpressure (Constant Cell Disruption System Ltd., UK, two passages at $25 \mathrm{kPsi}, 5^{\circ} \mathrm{C}$ ) cell debris was removed by low-speed centrifugation $\left(30 \mathrm{~min}, 12,074 \times g, 4^{\circ} \mathrm{C}\right)$, and membrane vesicles were collected by ultracentrifugation $(120 \mathrm{~min}, 193,727 \times g$, $4^{\circ} \mathrm{C}$ ). After that, the collected membrane vesicles were resuspended in buffer C ( $50 \mathrm{mM}$ Tris/HCl, $\mathrm{pH} 8.0,150 \mathrm{mM} \mathrm{NaCl}, 15 \%$ glycerol) to a final volume of $5 \mathrm{ml}$ per 1 liter of cell culture. Subsequently, aliquoted membrane vesicles were flash-frozen in liquid nitrogen and stored at $-80^{\circ} \mathrm{C}$. Bradford Protein Assay (Bio-Rad) was used to determine the total protein concentration in the prepared membrane vesicles.

Protein purification. Prepared membrane vesicles were rapidly thawed and immediately solubilized in buffer D $(50 \mathrm{mM}$ Tris/ $\mathrm{HCl}, \mathrm{pH} 8.0,150 \mathrm{mM} \mathrm{NaCl}$, $10 \mathrm{mM}$ imidazole, $10 \%$ glycerol, $1 \%$ (w/v) $n$-dodecyl- $\beta$-D-maltopyranoside (DDM, Anatrace)) at $4{ }^{\circ} \mathrm{C}$ for $1 \mathrm{~h}$, while gently rocking. To remove unsolubilized material the centrifugation step $\left(30 \mathrm{~min}, 442,907 \times \mathrm{g}, 4^{\circ} \mathrm{C}\right)$ was applied. After that, the supernatant was incubated for $1 \mathrm{~h}$ with $\mathrm{Ni}^{2+}$-sepharose resin (column volume of $0.5 \mathrm{ml})$ at $4{ }^{\circ} \mathrm{C}$, pre-equilibrated with $20 \mathrm{CV}$ of buffer $\mathrm{E}(50 \mathrm{mM}$ Tris $/ \mathrm{HCl}, \mathrm{pH} 8.0$, $150 \mathrm{mM} \mathrm{NaCl}, 15 \mathrm{mM}$ imidazole, $0.03 \%$ DDM). Next, the flow through was collected after the suspension had been poured into a 10-ml disposable column (Bio-Rad). The column material was washed with $10 \mathrm{ml}$ of buffer E. ZntB was eluted in three fractions of buffer $\mathrm{F}(50 \mathrm{mM}$ Tris/ $\mathrm{HCl}, \mathrm{pH} 8.0,250 \mathrm{mM} \mathrm{NaCl}$, $500 \mathrm{mM}$ imidazole, $0.03 \%(\mathrm{w} / \mathrm{v}) \mathrm{DDM}$ ) of 200,750 and $500 \mu \mathrm{l}$, respectively. The second elution fraction was treated with $2 \mathrm{mM}$ of EDTA to remove co-eluted $\mathrm{Ni}^{2+}$ ions and any residual zinc. Later on, the second elution fraction was subjected to size-exclusion chromatography using a Superdex 200 10/300 gel filtration column
(GE-Healthcare), pre-equilibrated with buffer G (50 mM Tris/HCl, $\mathrm{pH} 8.0$, $250 \mathrm{mM} \mathrm{NaCl}, 0.03 \%(\mathrm{w} / \mathrm{v}) \mathrm{DDM})$. Fractions containing purified were combined and used directly for proteoliposome reconstitution, or concentrated by the use of a Vivaspin 500 concentrating device with a molecular weight cutoff of $100 \mathrm{kDa}$ (Sartorius stedim) to a final concentration of $3-6 \mathrm{mg} \mathrm{ml}^{-1}$ with or without additional $1 \mathrm{mM}$ EDTA added when prepared for Cryo-EM.

Reconstitution into proteoliposomes. Reconstitution in proteoliposomes was performed as follows (please see ref. ${ }^{38}$ for details): polar lipids of E. coli and egg phosphatidylcholine (in 3:1 (w/w) ratio) were dissolved in chloroform, then dried in a rotary evaporator and subsequently resuspended in buffer containing $50 \mathrm{mM}$ $\mathrm{KPi}, \mathrm{pH} 7.5$ to the concentration of $20 \mathrm{mg} \mathrm{ml}^{-1}$. After three freeze-thaw cycles, large unilamellar vesicles (LUVs) were obtained and stored in liquid nitrogen. To prepare proteoliposomes, LUVs were extruded through a 400-nm-diameter polycarbonate filter (Avestin, 11 passages). Obtained liposomes were diluted to $4 \mathrm{mg} \mathrm{ml}$ ${ }^{-1}$ in buffer H (50 mM HEPES, pH 7.5) or buffer I (50 mM HEPES, pH 6.5) and subsequently destabilized beyond $R_{\text {sat }}$ with Triton X-100. Purified ZntB was added to the liposomes at a weight ratio of 1:250 (protein/lipid), followed by detergent removal using Bio-beads $\left(50 \mathrm{mg} \mathrm{ml}^{-1}\right.$, four times after $0.5 \mathrm{~h}, 1 \mathrm{~h}, 2 \mathrm{~h}$ and overnight incubation). Afterwards, proteoliposomes were collected by centrifugation ( $25 \mathrm{~min}$, $285,775 \times g, 4^{\circ} \mathrm{C}$ ) and resuspended in buffer $\mathrm{H}$ or buffer I to a lipid concentration of $10 \mathrm{mg} \mathrm{ml}^{-1}$. Finally, after three freeze-thaw cycles, obtained proteoliposomes were stored in liquid nitrogen until subsequent experiments.

Radiolabelled ${ }^{65} \mathrm{Zn}^{2+}$ transport assay. To use in the transport assay, proteoliposomes with desired $\mathrm{pH}$ were thawed and extruded through a $400-\mathrm{nm}$ pore size polycarbonate filter (Avestin, nine passages). Subsequently, two active units of ProTev Plus (Promega) were added to the protein sample and incubated overnight. The proteoliposomes were diluted 10 times to a final volume of $2 \mathrm{ml}$ in the same buffer. Following centrifugation step $\left(25 \mathrm{~min}, 285,775 \times g, 4^{\circ} \mathrm{C}\right)$, the proteoliposomes were resuspended in buffer $\mathrm{H}$ or I to a final concentration of $0.5 \mu \mathrm{g} \mathrm{ul}^{-1}$ $\mathrm{ZntB}$. For each time point in the transport assays, a reaction volume of $200 \mu \mathrm{l}$ of buffer (with desired pH) with $22 \mu \mathrm{M}$ of ${ }^{65} \mathrm{ZnCl}_{2}$ added, was incubated at $30^{\circ} \mathrm{C}$ while being stirred. Transport was initiated by adding $1 \mu \mathrm{g}$ of $\mathrm{ZntB}$, previously reconstituted in proteoliposomes. Stop buffer of $2 \mathrm{ml}$ (ice-cold outside buffer) 


\section{Table 1 Data collection and refinement statistics}

Data collection

Pixel size $(\AA)$
Microscope

Voltage

Micrographs collected (\#)

\section{Refinement}

Particles (\#)

Resolution $(\AA$; at $F S C=0.143$ )

CC (model to map fit)

RMS deviations

Bonds $(\AA)$

Angles $\left(^{\circ}\right)$

Chirality $\left(^{\circ}\right)$

Planarity $\left(^{\circ}\right)$

Titan KRIOS with K2-detector $300 \mathrm{kV}$

1.43

2655

333,490

4.2

$0.81(0.83)$

0.007

1.152

0.065

0.008

Validation

Clash score

Favoured rotamers (\%)

Ramachandran favoured (\%)

Ramachandran allowed (\%)

Ramachandran outliers (\%)

\section{2}

98.77

91.69

8.31

0 was added at the indicated time point, and the reaction was rapidly filtered over a BA-85 nitrocellulose filter. After the filter was washed with another $2 \mathrm{ml}$ of stop buffer, the levels of radioactivity were determined using a Packard Cobra II 5010 Gamma counter.

Fluorescent transport assays. Zinc transport was measured with the $\mathrm{Zn}^{2+}$-sensitive fluorophore FluoZin-1 (ThermoFisher, USA). To avoid bleaching of the fluorophore, the sample was shielded from the direct light as much as possible. FluoZin-1 (stock concentration $3 \mathrm{mM}$ in $\mathrm{H}_{2} \mathrm{O}$ ) was added to a final concentration of $5 \mu \mathrm{M}$ to the proteoliposomes with desired $\mathrm{pH}$. FluoZin-1 encapsulation was performed by three freeze-thaw cycles and subsequent extrusion through $0.4-\mu \mathrm{m}$ polycarbonate filters. Extravesicular dye was removed from $\sim 500 \mu \mathrm{l}$ of liposome suspension by size exclusion chromatography on a $2 \mathrm{ml}$ Sephadex G-75 column equilibrated with buffer $\mathrm{H}$ or I. Proteoliposomes were collected by ultracentrifugation $\left(25 \mathrm{~min}, 285,775 \times \mathrm{g}, 4^{\circ}\right.$ C), and the supernatant was removed. Proteoliposomes were resuspended with $10 \mu \mathrm{l}$ buffer $\mathrm{H}$ or I per $2.5 \mathrm{mg}$ of proteoliposomes (protein to lipid ratio 1:250). Transport assays with or without proton gradient were initiated by the addition of $10 \mathrm{mM}$ stock solution of zinc acetate to the desired final concentration. For each measurement, $0.3 \mathrm{mg}$ of proteoliposomes (protein to lipid ratio 1:250) was diluted in $1 \mathrm{ml}$ of desired buffer. A fluorescence time course was measured in a $1 \mathrm{ml}$ cuvette with a stirrer using an excitation wavelength of $490 \mathrm{~nm}$ and an emission wavelength of $525 \mathrm{~nm}$. Experiments with empty liposomes were performed in parallel as controls. Initial transport rates $\left(\Delta \mathrm{F} \mathrm{s}^{-1}\right)$ were calculated by performing a linear regression on the transport data between 1 and $10 \mathrm{~s}$ after addition of zinc acetate. The resulting data was fitted to a Michaelis-Menten equation. All measurements were at least triplicated.

For $\mathrm{H}^{+}$transport assays, the lumenal buffer of the proteoliposomes was exchanged for buffer $\mathrm{J}(5 \mathrm{mM}$ HEPES $\mathrm{pH}$ 6.7) by resuspension of the liposomes in this buffer followed by three freeze-thaw cycles and extrusion through $0.4-\mu \mathrm{m}$ polycarbonate filters. Proteoliposomes were collected by ultracentrifugation $\left(25 \mathrm{~min}, 285,775 \times g, 4^{\circ} \mathrm{C}\right.$ ), and the supernatant was removed. Proteoliposomes were resuspended with $10 \mu \mathrm{l}$ buffer J per $2.5 \mathrm{mg}$ of proteoliposomes (protein to lipid ratio 1:250). For each measurement, $0.3 \mathrm{mg}$ of proteoliposomes was diluted in $1 \mathrm{ml}$ of buffer K (5 mM HEPES, pH 6.7, $150 \mathrm{nM}$ ACMA). A fluorescence time course was measured in a $1 \mathrm{ml}$ cuvette with a stirrer using an excitation wavelength of $419 \mathrm{~nm}$ and an emission wavelength of $483 \mathrm{~nm}$; zinc was added after 3 min of equilibration time. Experiments with empty liposomes were performed in parallel as controls. All measurements were triplicated.

Isothermal titration calorimetry. ITC200 instrument (MicroCal) was used to perform all ITC experiments. The thermally equilibrated ITC cell was filled with $280 \mu \mathrm{l}$ of ZntB in buffer G (10-15 $\mu \mathrm{M})$ and studied substrates (in the same buffer) were titrated into the cell. Temperature was fixed at $25^{\circ} \mathrm{C}$. Analysis of data was performed using the origin-based software provided by MicroCal.

Single particle cryo-electron microscopy. The purified $\mathrm{ZntB}$ sample was adjusted to a final concentration of $\sim 10 \mathrm{mg} \mathrm{ml}^{-1}$. Aliquots of $3 \mu \mathrm{l}$ were applied to a freshly glow-discharged holey carbon grids (Quantifoil Au R1.2/1.3, 300 mesh), excess liquid was blotted for $4-5 \mathrm{~s}$ using a FEI Vitrobot Mark IV and the sample was plunge frozen in liquid ethane at a temperature of approximately $100 \mathrm{~K}$. TEM grids were transferred into a Titan Krios $300 \mathrm{keV}$ microscope (FEI, Netherlands), equipped with a K2 direct-electron detector. Zero-loss images were recorded semiautomatically, using the UCSF Image4 script ${ }^{39}$. The GIF-quantum energy filter was adjusted to a slit width of $20 \mathrm{eV}$. Images were collected at a nominal magnification of $\times 81,000$ (yielding a pixel size of $1.43 \AA$ ) and a defocus range of -1.5 to $-3.0 \mu \mathrm{m}$. A total of 2655 movie images were collected with 24 frames dose-fractionated over $18 \mathrm{~s}$, in super-resolution counting mode.

Beam-induced motion in the raw movie frames was corrected for using wholeframe motion correction with MOTIONCORR $1.0^{40}$, followed by contrast transfer function (CTF) estimation using gctf ${ }^{41}$. All subsequent data processing steps were performed using the RELION 2.0 software suite ${ }^{42}$. References for template-based particle picking were obtained from two-dimensional (2D) classes obtained from manually picked particles from a subset of micrographs. The initial run of template-based algorithm picked 1 million particles from all 2655 images. To reduce the number of false-positive particle picks from the initial template-based particle picking, several rounds of $2 \mathrm{D}$ classification were applied to the full extracted data set, resulting in a subset of 333,490 particle projections. The resulting particles were submitted to three-dimensional auto-refinement, particlebased motion correction and damage-based weighting of individual frames ${ }^{43}$. An additional round of $2 \mathrm{D}$ classification was performed on these 'polished' particles to further discard false-positive or low-quality particles. The obtained map was used for manual model building in $\operatorname{Coot}^{44}$ using the previously published CorA structure (pdb id: $4 \mathrm{IOU}$ ) as a reference model. Refinement was performed in Phenix ${ }^{45}$ with the final validation check in Molprobity ${ }^{46}$. The ' $\mathrm{Zn}^{2+}$-bound' model

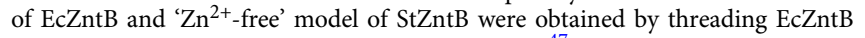
sequence into StZntB model with the Phyre2 server ${ }^{47}$. Electrostatic potentials were calculated with $\mathrm{APBS}^{48}$ after the initial preparation of files at PDB2PQR server ${ }^{49}$. Images were prepared with the open source version of PyMol (https://sourceforge. net/projects/pymol/).

Data availability. Atomic coordinates and the corresponding electron microscopy density map are deposited in the Protein Data Bank and the Electron Microscopy Data Bank under accession number 5N9Y and EMD-3605, respectively. Other data are available from the corresponding authors upon reasonable request.

Received: 30 January 2017 Accepted: 18 September 2017

Published online: 03 November 2017

\section{References}

1. Capdevila, D. A., Wang, J. \& Giedroc, D. P. Bacterial strategies to maintain zinc metallostasis at the host-pathogen interface. J. Biol. Chem. 291, 20858-20868. (2016).

2. Kehl-Fie, T. E. \& Skaar, E. P. Nutritional immunity beyond iron: a role for manganese and zinc. Curr. Opin. Chem. Biol. 14, 218-224 (2010).

3. Blindauer, C. A. Advances in the molecular understanding of biological zinc transport. Chem. Commun. 51, 4544-4563 (2015).

4. Ong, C.-L. Y., Gillen, C. M., Barnett, T. C., Walker, M. J. \& McEwan, A. G. An antimicrobial role for zinc in innate immune defense against group A Streptococcus. J. Infect. Dis. 209, 1500-1508 (2014).

5. Blindauer, C. A. et al. A metallothionein containing a zinc finger within a fourmetal cluster protects a bacterium from zinc toxicity. Proc. Natl Acad. Sci. USA 98, 9593-9598 (2001).

6. Herzberg, M., Bauer, L., Kirsten, A. \& Nies, D. H. Interplay between seven secondary metal uptake systems is required for full metal resistance of Cupriavidus metallidurans. Metallomics 8, 313-326 (2016).

7. Karlinsey, J. E., Maguire, M. E., Becker, L. A., Crouch, M.-L. V. \& Fang, F. C. The phage shock protein PspA facilitates divalent metal transport and is required for virulence of Salmonella enterica sv. Typhimurium. Mol. Microbiol. 78, 669-685 (2010).

8. Ammendola, S. et al. High-affinity $\mathrm{Zn}^{2+}$ uptake system $\mathrm{ZnuABC}$ is required for bacterial zinc homeostasis in intracellular environments and contributes to the virulence of Salmonella enterica. Infect. Immun. 75, 5867-5876 (2007).

9. Perry, R. D., Bobrov, A. G. \& Fetherston, J. D. The role of transition metal transporters for iron, zinc, manganese, and copper in the pathogenesis of Yersinia pestis. Metallomics 7, 965-978 (2015).

10. Wang, K. et al. Structure and mechanism of $\mathrm{Zn}^{2+}$-transporting P-type ATPases. Nature 514, 518-522 (2014).

11. Lu, M. \& Fu, D. Structure of the zinc transporter YiiP. Science 317, 1746-1748 (2007).

12. Worlock, A. J. \& Smith, R. L. ZntB is a novel $\mathrm{Zn}^{2+}$ transporter in Salmonella enterica serovar Typhimurium. J. Bacteriol. 184, 4369-4373 (2002).

13. Payandeh, J., Pfoh, R. \& Pai, E. F. The structure and regulation of magnesium selective ion channels. Biochim. Biophys. Acta 1828, 2778-2792 (2013). 
14. Tan, K. et al. Structure and electrostatic property of cytoplasmic domain of ZntB transporter. Protein Sci. 18, 2043-2052 (2009).

15. Wan, Q. et al. X-ray crystallography and isothermal titration calorimetry studies of the Salmonella zinc transporter ZntB. Structure 19, 700-710 (2011).

16. Nordin, N. et al. Exploring the structure and function of Thermotoga maritima CorA reveals the mechanism of gating and ion selectivity in $\mathrm{Co}^{2+} / \mathrm{Mg}^{2+}$ transport. Biochem. J. 451, 365-374 (2013).

17. Guskov, A. et al. Structural insights into the mechanisms of $\mathrm{Mg}^{2+}$ uptake, transport, and gating by CorA. Proc. Natl Acad. Sci. USA 109, 18459-18464 (2012).

18. Guskov, A. \& Eshaghi, S. The mechanisms of $\mathrm{Mg}^{2+}$ and $\mathrm{Co}^{2+}$ transport by the CorA family of divalent cation transporters. Curr. Top. Membr. 69, 393-414 (2012).

19. Dudev, T. \& Lim, C. Importance of metal hydration on the selectivity of $\mathrm{Mg}^{2+}$ versus $\mathrm{Ca}^{2+}$ in magnesium ion channels. J. Am. Chem. Soc. 135, 17200-17208 (2013).

20. Bock, C. W., Katz, A. K. \& Glusker, J. P. Hydration of zinc ions: a comparison with magnesium and beryllium ions. J. Am. Chem. Soc. 117, 3754-3765 (1995).

21. Ohtaki, H. \& Radnai, T. Structure and dynamics of hydrated ions. Chem. Rev. 93, 1157-1204 (1993).

22. Marcus, Y. Ionic radii in aqueous solutions. Chem. Rev. 88, 1475-1498 (1988).

23. Inada, Y., Mohammed, A. M., Loeffler, H. H. \& Rode, B. M. Hydration structure and water exchange reaction of nickel(II) ion: classical and QM/MM simulations. J. Phys. Chem. A 106, 6783-6791 (2002).

24. Xia, Y. et al. $\mathrm{Co}^{2+}$ selectivity of Thermotoga maritima CorA and its inability to regulate $\mathrm{Mg}^{2+}$ homeostasis present a new class of CorA proteins. J. Biol. Chem. 286, 16525-16532 (2011).

25. Gibson, M. M., Bagga, D. A., Miller, C. G. \& Maguire, M. E. Magnesium transport in Salmonella typhimurium: the influence of new mutations conferring $\mathrm{Co}^{2+}$ resistance on the CorA $\mathrm{Mg}^{2+}$ transport system. Mol. Microbiol. 5, 2753-2762 (1991)

26. Rahman, M. et al. Probing metal ion substrate-binding to the E. coli ZitB exporter in native membranes by solid state NMR. Mol. Membr. Biol. 25, 683-690 (2008).

27. Lunin, V. V. et al. Crystal structure of the CorA $\mathrm{Mg}^{2+}$ transporter. Nature 440, 833-837 (2006).

28. Matthies, D. et al. Cryo-EM structures of the magnesium channel CorA reveal symmetry break upon gating. Cell 164, 747-756 (2016).

29. Cleverley, R. M. et al. The Cryo-EM structure of the CorA channel from Methanocaldococcus jannaschii in low magnesium conditions. Biochim. Biophys. Acta 1848, 2206-2215 (2015).

30. Pfoh, R. et al. Structural asymmetry in the magnesium channel CorA points to sequential allosteric regulation. Proc. Natl Acad. Sci. USA 109, 18809-18814 (2012).

31. Romani, A. M. P. Cellular magnesium homeostasis. Arch. Biochem. Biophys. 512, 1-23 (2011).

32. Outten, C. E. \& O'Halloran, T. V. Femtomolar sensitivity of metalloregulatory proteins controlling zinc homeostasis. Science 292, 2488-2492 (2001).

33. Wang, D., Hurst, T. K., Thompson, R. B. \& Fierke, C. A. Genetically encoded ratiometric biosensors to measure intracellular exchangeable zinc in Escherichia coli. J. Biomed. Opt. 16, 087011 (2011).

34. Elías, A. et al. The ActP acetate transporter acts prior to the PitA phosphate carrier in tellurite uptake by Escherichia coli. Microbiol. Res. 177, 15-21 (2015).

35. Maynaud, G. et al. CadA of Mesorhizobium metallidurans isolated from a zincrich mining soil is a $\mathrm{P}(\mathrm{IB}-2)$-type ATPase involved in cadmium and zinc resistance. Res. Microbiol. 165, 175-189 (2014).

36. Chaoprasid, P., Nookabkaew, S., Sukchawalit, R. \& Mongkolsuk, S. Roles of Agrobacterium tumefaciens $\mathrm{C} 58 \mathrm{ZntA}$ and $\mathrm{ZntB}$ and the transcriptional regulator $\mathrm{ZntR}$ in controlling $\mathrm{Cd}^{2+} / \mathrm{Zn}^{2+} / \mathrm{Co}^{2+}$ resistance and the peroxide stress response. Microbiology 161, 1730-1740 (2015).

37. Savitsky, P. et al. High-throughput production of human proteins for crystallization: the SGC experience. J. Struct. Biol. 172, 3-13 (2010).

38. Geertsma, E. R., Nik Mahmood, N. A. B., Schuurman-Wolters, G. K. \& Poolman, B. Membrane reconstitution of ABC transporters and assays of translocator function. Nat. Protoc. 3, 256-266 (2008).

39. Li, X., Zheng, S., Agard, D. A. \& Cheng, Y. Asynchronous data acquisition and on-the-fly analysis of dose fractionated cryoEM images by UCSFImage. J. Struct. Biol. 192, 174-178 (2015).
40. Li, X. et al. Electron counting and beam-induced motion correction enable near-atomic-resolution single-particle cryo-EM. Nat. Methods 10, 584-590 (2013).

41. Zhang, K. Gctf: Real-time CTF determination and correction. J. Struct. Biol. 193, 1-12 (2016).

42. Scheres, S. H. W. RELION: implementation of a Bayesian approach to cryo-EM structure determination. J. Struct. Biol. 180, 519-530 (2012).

43. Scheres, S. H. Beam-induced motion correction for sub-megadalton cryo-EM particles. Elife 3, e03665 (2014).

44. Emsley, P., Lohkamp, B., Scott, W. G. \& Cowtan, K. Features and development of Coot. Acta. Crystallogr. D Biol. Crystallogr. 66, 486-501 (2010).

45. Adams, P. D. et al. PHENIX: a comprehensive Python-based system for macromolecular structure solution. Acta Crystallogr. D Biol. Crystallogr. 66, 213-221 (2010).

46. Chen, V. B. et al. MolProbity: all-atom structure validation for macromolecular crystallography. Acta. Crystallogr. D Biol. Crystallogr. 66, 12-21 (2010).

47. Kelley, L. A., Mezulis, S., Yates, C. M., Wass, M. N. \& Sternberg, M. J. E. The Phyre2 web portal for protein modeling, prediction and analysis. Nat. Protoc. 10, 845-858 (2015)

48. Baker, N. A., Sept, D., Joseph, S., Holst, M. J. \& McCammon, J. A. Electrostatics of nanosystems: application to microtubules and the ribosome. Proc. Natl Acad. Sci. USA 98, 10037-10041 (2001).

49. Dolinsky, T. J. et al. PDB2PQR: expanding and upgrading automated preparation of biomolecular structures for molecular simulations. Nucleic Acids Res. 35, W522-W525 (2007)

\section{Acknowledgements}

We are grateful to M. Guskova for help with figures preparation. This research was supported by HFSP fellowship (LTF000087/2015-L) to C.G. and NWO Vidi grant 723.014.002 to A.G.

\section{Author contributions}

A.G. conceived the project. Expression, purification, ITC, radioactive zinc uptakes and transport assays were performed by A.S. Cryo-EM was carried out by C.G. and S.H.W.S Model building and refinement was done by A.G. A.S., C.G., D.J.S., S.H.W.S. and A.G. analysed the data. A.G. and D.J.S. wrote the manuscript with input from all other authors.

\section{Additional information}

Supplementary Information accompanies this paper at doi:10.1038/s41467-017-01483-7.

Competing interests: The authors declare no competing financial interests.

Reprints and permission information is available online at http://npg.nature.com/ reprintsandpermissions/

Publisher's note: Springer Nature remains neutral with regard to jurisdictional claims in published maps and institutional affiliations.

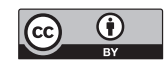

Open Access This article is licensed under a Creative Commons Attribution 4.0 International License, which permits use, sharing, adaptation, distribution and reproduction in any medium or format, as long as you give appropriate credit to the original author(s) and the source, provide a link to the Creative Commons license, and indicate if changes were made. The images or other third party material in this article are included in the article's Creative Commons license, unless indicated otherwise in a credit line to the material. If material is not included in the article's Creative Commons license and your intended use is not permitted by statutory regulation or exceeds the permitted use, you will need to obtain permission directly from the copyright holder. To view a copy of this license, visit http://creativecommons.org/ licenses/by/4.0/

(c) The Author(s) 2017 